\title{
Rapid thermal annealing of InAs/GaAs quantum dots under a GaAs proximity cap
}

\author{
Adam Babinski ${ }^{\text {a) }}$ \\ Institute of Experimental Physics, Warsaw University, Hozÿa 69, 00-681 Warsaw, Poland \\ J. Jasinski ${ }^{\text {b) b) }}$ \\ Materials Science Division, Lawrence Berkeley National Laboratory, 1 Cyclotron Road, \\ Berkeley, \\ California 94720 \\ R. Bozek, A. Szepielow, and J. M. Baranowski \\ Institute of Experimental Physics, Warsaw University, Hoza 69, 00-681 Warsaw, Poland
}

\begin{abstract}
The effect of postgrowth rapid thermal annealing (RTA) on GaAs proximitycapped structures with self-assembled InAs/GaAs quantum dots (QDs) is investigated using transmission electron microscopy (TEM) and photoluminescence (PL). As can be seen from the TEM images, QDs increase their lateral sizes with increasing annealing temperature (up to $700{ }^{\circ} \mathrm{C}$ ). QDs cannot be distinguished after RTA at temperature $800{ }^{\circ} \mathrm{C}$ or higher, and substantial thickening of the wetting layer can be seen instead. The main PL peak blueshifts as a result of RTA. We propose that in the as-grown sample as well, as in samples annealed at temperatures up to $700{ }^{\circ} \mathrm{C}$, the peak is due to the QDs. After RTA at $800{ }^{\circ} \mathrm{C}$ and higher the PL peak is due to a modified wetting layer. Relatively fast dissolution of QDs is explained in terms of strain-induced lateral $\mathrm{Ga} / \mathrm{In}$ interdiffusion. It is proposed that such a process may be of importance in proximity-capped RTA, when no group-III vacancy formation takes place at the sample/capping interface.
\end{abstract}

Thermally induced intermixing of semiconductor low-dimensional structures attracts attention as a way of tuning their properties. 1 In recent years, this technique has also been applied to semiconductor quantum dots (QDs). ${ }^{2}$ Several papers have been published on InGaAs/GaAs QDs intermixing, ${ }^{3-13}$ and it is generally accepted that such a procedure leads to a blueshift and a narrowing of optical emission from QDs. The postgrowth thermal annealing is usually performed in a growth chamber ${ }^{4,8}$ or in a rapid thermal annealing (RTA) system with $\mathrm{SiO}_{2}$ capping ${ }^{5,9,12,13}$ or proximity capping (which means an annealing with a piece of GaAs substrate in close proximity to the sample surface) ${ }^{3,6,7}$ It is also known that RTA of samples without any capping leads to surface degradation due to As outdiffusion. ${ }^{7}$ Although it is well established that sample capping during thermal cycling of strained InGaAs/GaAs multiquantum wells can critically influence the results of the annealing procedure, ${ }^{14}$ comparative studies of the effect on thermal annealing of QDs have been published just recently. ${ }^{12,13}$ In this letter, we report on the effect of RTA on InAs/GaAs QDs with GaAs proximity capping. We show that RTA can lead to complete dissolution of QDs and to a significant broadening of the wetting layer (WL).

\footnotetext{
a) Electronic mail: Adam.Babinski@fuw.edu.pl

b) On leave from Institute of Experimental Physics, Warsaw University, Warsaw, Poland.
} 
The structure investigated in this study was grown by metalorganic vapor phase epitaxy. After growth of the GaAs buffer layer at $650{ }^{\circ} \mathrm{C}$ on a nominally (100)-oriented GaAs substrate, the temperature was lowered to $470{ }^{\circ} \mathrm{C}$ and self-assembled InAs QDs were grown in Stranski-Krastanow mode. Then, the temperature was increased to $500{ }^{\circ} \mathrm{C}$ while growing $100 \mathrm{~nm}$ of the GaAs capping layer. Samples cut from the wafer were proximity capped and RTA treated in nitrogen ambient for $30 \mathrm{~s}$ at $600,700,800,850$, 900 , and $950^{\circ} \mathrm{C}$. The surfaces of investigated samples were not affected during the RTA procedure. The microstructures of the as-grown and all annealed samples were studied using transmission electron microscopy (TEM). Cross-sectional TEM specimens were prepared from the samples by a standard method of mechanical thinning followed by ion milling. In addition, plan-view specimens were prepared from the as-grown sample. Wet etching in a 5\% methanol solution of bromine was applied. All annealed samples as well as the as-grown one were studied by photoluminescence (PL). Measurements were performed at liquid-helium temperature with laser excitation $(15780 \mathrm{~nm})$. The signal was dispersed by a monochromator and collected using a liquid-nitrogen-cooled germanium detector.

The presence of high-density self-assembled QDs in the as-grown sample was confirmed by plan-view TEM (Fig. 1). QDs are clearly visible in the bright-field TEM images taken from the plan-view samples under two-beam $(0, \mathrm{~g})$ condition, where $g$ was of the (220)-type reflection. The average size of these QDs was about $10 \mathrm{~nm}$. Their density, as estimated from the plan-view observation, was of the order of $10^{11} \mathrm{~cm}^{-2}$. The characteristic contrast arising from the dots (the contrast is dark on one side of the island and bright on the other side) suggests that the QDs present in the as-grown samples were fully strained. ${ }^{4}$ There is also no indication of any strain relaxation in the form of large, dislocated islands or dislocations threading through the capping layer.

The QDs can also be seen in the cross-sectional TEM image of the as-grown sample [Fig. 2(a)]. RTA results in substantial changes of the sample microstructure (Fig. 2). Well-defined QDs can still be seen in samples annealed at 600 and $700{ }^{\circ} \mathrm{C}$ [see Figs. 2(b) and 2(c), respectively]. The lateral sizes of the QDs increase with increasing RTA temperature. In samples annealed at $800{ }^{\circ} \mathrm{C}$ or higher temperatures no QDs were observed. A broadening of the modified

WL can be observed instead. The layer thickness increases to approximately $3 \mathrm{~nm}$ after annealing at $800{ }^{\circ} \mathrm{C}$ [Fig. 2(d)] and to about $8 \mathrm{~nm}$ after annealing at $950{ }^{\circ} \mathrm{C}$ [Fig. 2(e)]. RTA-induced changes in the microstructure can be confronted with the results of the PL measurements. The PL spectrum of the as-grown sample comprises two features, as can be seen in Fig. 3. The main PL peak at $1.155 \mathrm{eV}$ is due to optical recombination within the InAs QDs. Its inhomogeneous broadening reflects the QD size distribution and fluctuations in their composition. The PL peak observed at $1.42 \mathrm{eV}$ is due to the InAs WL (1 ML thick as observed from high-resolution TEM). Annealing at $600{ }^{\circ} \mathrm{C}$ (for $30 \mathrm{~s}$ ) results in no significant change to the QDs PL peak position (with a slight decrease of its intensity) and in a substantial decrease of the WL PL intensity. ${ }^{3}$ Further changes to the PL spectrum can be observed after thermal treatment at $700{ }^{\circ} \mathrm{C}$ or higher temperature. RTA treatment of the samples results in a quenching of the WL PL (with a weak feature still present after an annealing at $\mathrm{T}=700{ }^{\circ} \mathrm{C}$ ). One peak dominates the PL spectra for samples annealed at $\mathrm{T}>700{ }^{\circ} \mathrm{C}$ with the energy position shifting from $1.33 \mathrm{eV}\left(700{ }^{\circ} \mathrm{C}\right)$ 
to $1.427 \mathrm{eV}\left(950^{\circ} \mathrm{C}\right)$. In addition, a significant narrowing and intensity increase of this PL peak takes place with the increase of the annealing temperature.

The observed changes in the microstructure and PL of the annealed samples can be interpreted as follows. RTA at the lowest temperatures $\left(600\right.$ and $\left.700{ }^{\circ} \mathrm{C}\right)$ results in intermixing of the QDs. Mainly, the lateral sizes of the QDs increase as a results of that process. After RTA at $800{ }^{\circ} \mathrm{C}$, the QDs cannot be distinguished in the TEM images. This suggests that the QDs dissolve into the surrounding WL. The main PL peak seen from such a sample must be due to the modified with increasing RTA temperature. Diffusion coefficients for the intermixed WL can be estimated from their thickness, measured by TEM. It was assumed that all the indium present before annealing (found from the growing parameters) was uniformly redistributed during RTA. The Fick's diffusion equation, in the form of the error function solution, ${ }^{15}$ has been employed. It has been assumed that the WL thickness found from TEM corresponds to the full width at half maximum of the theoretical indium composition. Diffusion constants found from such analysis (from $2.3 \mathrm{x}$ $10^{-16} \mathrm{~cm}^{2} / \mathrm{s}$ at $800{ }^{\circ} \mathrm{C}$ to $4.1 \times 10^{-16} \mathrm{~cm}^{2} / \mathrm{s}$ at $900{ }^{\circ} \mathrm{C}$, and $1.7 \times 10^{-15} \mathrm{~cm}^{2} / \mathrm{s}$ at $950{ }^{\circ} \mathrm{C}$ ) are similar to those reported for GaAs proximity-capped intermixed $\operatorname{In}_{0.35} \mathrm{Ga}_{0.65} \mathrm{As} / \mathrm{GaAs}$ multiquantum wells. ${ }^{14}$

The dissolution of QDs observed at $\mathrm{T}=800{ }^{\circ} \mathrm{C}$ is different from the previously reported effect of RTA on $\mathrm{SiO}_{2}$-capped samples with InAs/GaAs QDs. It was shown that the three-dimensional character of the QD confinement potential could be retained even after RTA at relatively high temperature [30 s (Ref. 5) or $60 \mathrm{~s}\left(\right.$ Ref. 13) at $900{ }^{\circ} \mathrm{C}$ ] in such samples. In our opinion the GaAs proximity capping during the RTA procedure is responsible for the relatively fast dissolution of the QDs in our samples. It is well known that the interdiffusion process strongly depends on the density of defects such as vacancies, interstitials, and dislocations. The number of $\mathrm{Ga}$ vacancies available for $\mathrm{In} / \mathrm{Ga}$ interdiffusion in proximity-capped samples are limited to those existing in the sample. This results very likely in a relatively weak intermixing 14 across the dot/cap interface in such samples. Another process can be of importance during the RTA treatment of proximity-capped structures with QDs. This is the non-Fickian strain-enhanced interdiffusion, ${ }^{16}$ which has been suggested to explain some of the results of the RTA treatment of InGaAs/GaAs QDs. ${ }^{3,7}$ The strain in regions around the QDs (Ref. 17) enhances the vacancy concentration, which increases the lateral In/Ga interdiffusion. In such a process $\mathrm{Ga}$ atoms would replace In atoms in the highly strained region around the QD base. Such behavior has already been reported in the uncapped InP/GaAs system. ${ }^{18}$ Laterally en hanced interdiffusion could cause relatively fast dissolution of the QDs. After RTA at 600 and $700{ }^{\circ} \mathrm{C}$ an increase in the QD lateral sizes due to interdiffusion is observed. Simultaneously, the area covered with the 1-ML-thick WL decreases, which could explain quenching of the WL emission. A further increase in the QD lateral sizes, which occurs after RTA at higher temperatures, cancels the lateral confinement of the carriers. The Blueshift of the PL peak observed after RTA in this temperature range is due to an intermixing of the modified WL. On the contrary, a large number of Ga vacancies form at the $\mathrm{SiO}_{2} / \mathrm{GaAs}$ interface during RTA with the $\mathrm{SiO}_{2}$ cap, which is due to a fast $\mathrm{Ga}$ outdiffusion into the $\mathrm{SiO}_{2}$ layer during thermal annealing. ${ }^{19} \mathrm{Ga}$ vacancies diffuse into the QDs region during RTA, enhancing the $\mathrm{In} / \mathrm{Ga}$ interdiffusion through a dot/cap interface. ${ }^{12,13}$ That process affects mainly the QD height, which results in a blueshift and narrowing of the optical emission with no destruction of the three- 
dimensional carrier confinement in the QDs. It is very likely that the density of the Ga vacancies introduced during RTA with $\mathrm{SiO}_{2}$ capping is larger than the concentration of strain- induced vacancies around the QDs (especially in the case of low-density QDs). This would explain, presumably, a weaker lateral intermixing and preserve the threedimensional confinement in $\mathrm{SiO}_{2}$-capped RTA QDs.

In conclusion, we studied the effect of thermal treatment on the proximity-capped structures with self-assembled InAs/GaAs QDs. TEM shows a complete dissolution of QDs into surrounding WL after RTA at $\mathrm{T}=800{ }^{\circ} \mathrm{C}$ for $30 \mathrm{~s}$. Substantial thickening of the modified WL is observed after RTA at higher temperatures. It is proposed that strainenhanced lateral $\mathrm{In} / \mathrm{Ga}$ interdiffusion is responsible for the fast disappearance of the QDs in the investigated samples. This process may be of importance in proximity-capped annealing, when no group-III vacancy formation takes place at the sample/capping interface.

The authors are grateful to Dr. E. Kaminska from the Institute of Electron Technology, Warsaw, Poland for the RTA processing of the investigated samples. This work was supported in part by Polish Committee for Scientific Research Grant No. 7 T08 A 04017 and by the U.S. Department of Energy under Contract No. DE-AC0376SF00098. The use of the facilities at the National Center for Electron Microscopy at the Lawrence Berkeley National Laboratory is greatly appreciated.

\section{References}

1. For a review on quantum-well intermixing, see J. H. Marsh, Semicond. Sci. Technol. 8, 1136 (1993).

2. For a review on quantum dots, see, e.g., Quantum Dot Heterostructures, edited by D. Bimberg, M. Grundmann, and N. N. Ledentsov (Wiley, Chichester, 1998); L. Jacak, P. Hawrylak, and A. Wojs, Quantum Dots (Springer, Berlin, 1998).

3. R. Leon, Y. Kim, C. Jagadish, M. Gal, J. Zou, and D. J. Cockayne, Appl. Phys. Lett. 69, 1888 (1996).

4. A. O. Kosogov, P. Werner, U. Goesele, N. N. Ledentsov, D. Bimberg, V. M. Ustinov, A. Y. Egorov, A. E. Zhukov, P. S. Kopev, N. A. Berst, and Zh. I. Alferov, Appl. Phys. Lett. 69, 3072 (1996).

5. S. Malik, C. Roberts, R. Murray, and M. Pate, Appl. Phys. Lett. 71, 1987 (1997).

6. R. Leon, S. Fafard, P. G. Piva, S. Ruvimov, and Z. Liliental-Weber, Phys. Rev. B 58, R4262 (1998!).

7. C. Lobo, R. Leon, S. Fafard, and P. G. Piva, Appl. Phys. Lett. 72, 2850 (1998).

8. F. Heinrichsdorff, M. Grundmann, O. Stier, A. Krost, and D. Bimberg, J. Cryst. Growth 195, 540 (1998).

9. S. J. Xu, X. C. Wang, S. J. Chua, C. H. Wang, W. J. Fan, J. Jiang, and X. G. Xie, Appl. Phys. Lett. 72, 3335 (1998).

10. S. Fafard and C. N. Allen, Appl. Phys. Lett. 75, 2374 (1999).

11. S. Fafard, Z. R. Wasilewski, C. N. Allen, D. Picard, M. Spanner, J. P. McCaffrey, and P. G. Piva, Phys. Rev. B 59, 15368 (1999).

12. A. Bhattacharyya, A. Saher Helmy, A. C. Bryce, E. A. Avrutin, and J. H. Marsh, J. Appl. Phys. 88, 4619 (2000). 
13. N. Perret, D. Morris, L. Franchomme-Fosse, R. Cote, S. Fafard, V. Aimez, and J. Beauvais, Phys. Rev. B 62, 5092 (2000).

14. S. Burkner, M. Baeumler, J. Wagner, E. C. Larkins, W. Rothermund, J. D. Ralston, and J. Appl. Phys. 79, 6818 (1996).

15. J. Cibert, P. M. Petroff, D. J. Werder, S. J. Pearton, A. C. Gossard, and J. H. English, Appl. Phys. Lett. 49, 223 (1986).

16. S. W. Ryu, I. Kim, B. D. Choe, and W. G. Jeong, Appl. Phys. Lett. 67, 1417 (1995).

17. L. J. M. Selen, L. J. van Ijzendoorn, M. J. A. de Voigt, and P. M. Koenraad, Phys. Rev. B 61,8270 (2000).

18. J. Johansson, W. Seifert, V. Zwiller, T. Junno, and L. Samuelson, Appl. Surf. Sci. 134,47 (1998).

19. A. H. Van Ommen, Appl. Surf. Sci. 30, 244 (1987). 


\section{Figures captions}

Figure 1.

Bright field TEM image of the plan-view of the as-grown sample.

Figure 2.

High resolution electron microscopy images of samples: as-grown (a) and annealed at $600^{\circ} \mathrm{C}(\mathrm{b}), 700^{\circ} \mathrm{C}$ (c) $800^{\circ} \mathrm{C}(\mathrm{d})$ and $950^{\circ} \mathrm{C}(\mathrm{e})$.

Figure 3.

Photoluminescence $(T=4.2 \mathrm{~K})$ from the as-grown and annealed samples with $\mathrm{InAs} / \mathrm{GaAs}$ QDs. 


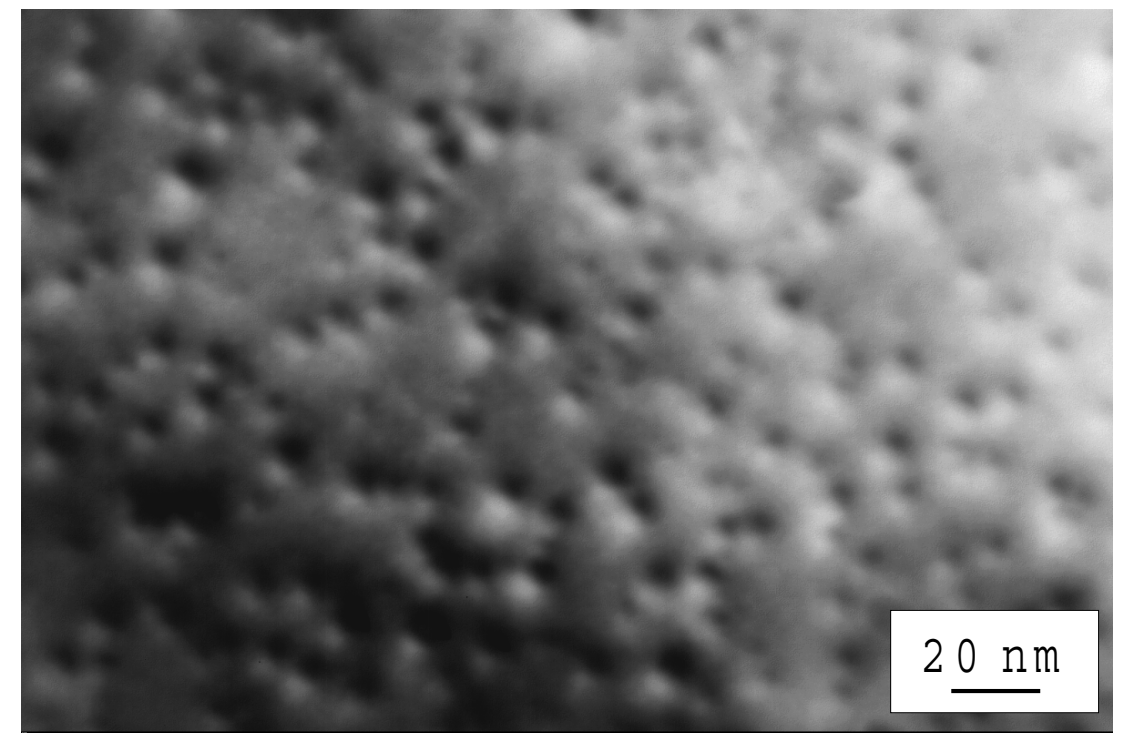

Figure 1 

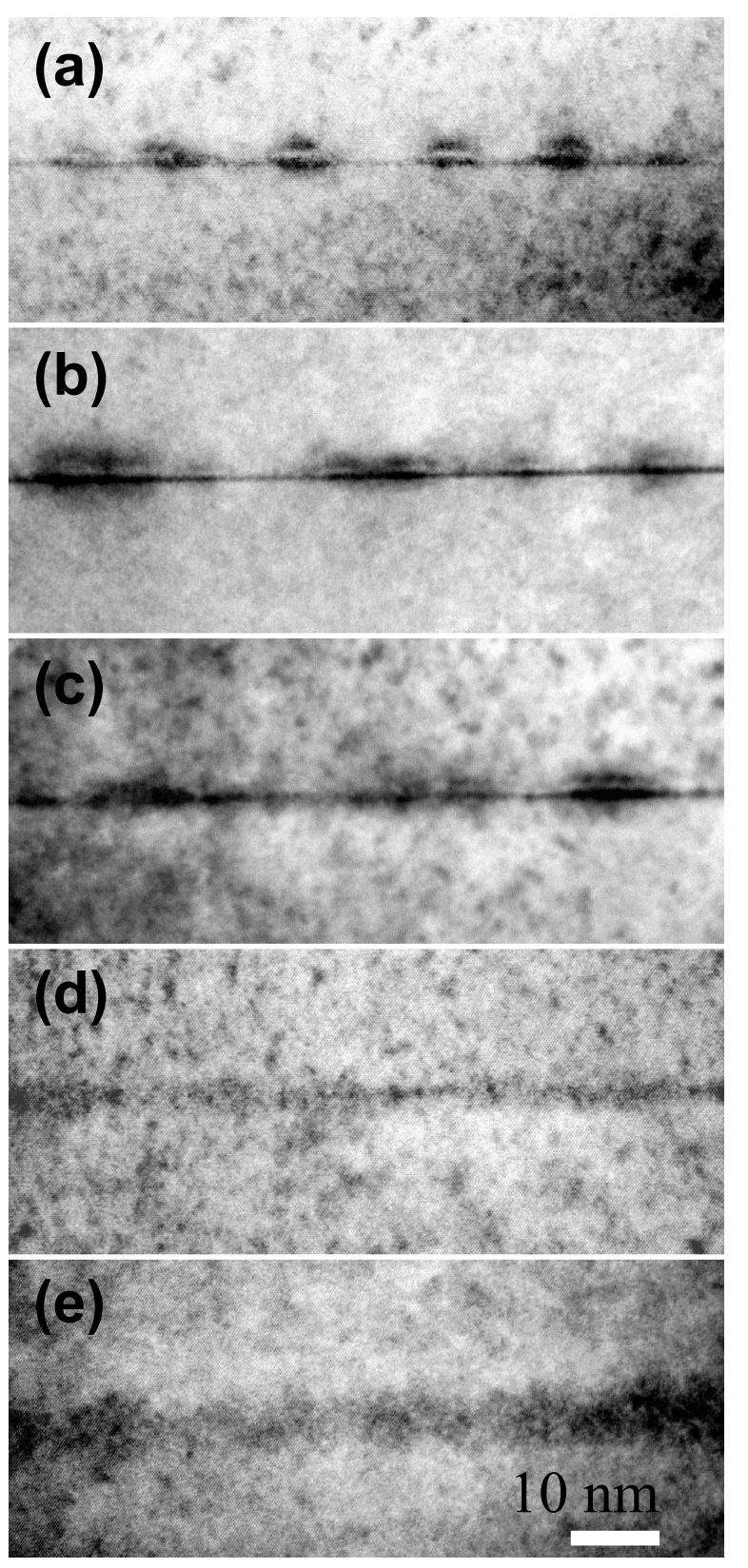

Figure 2 


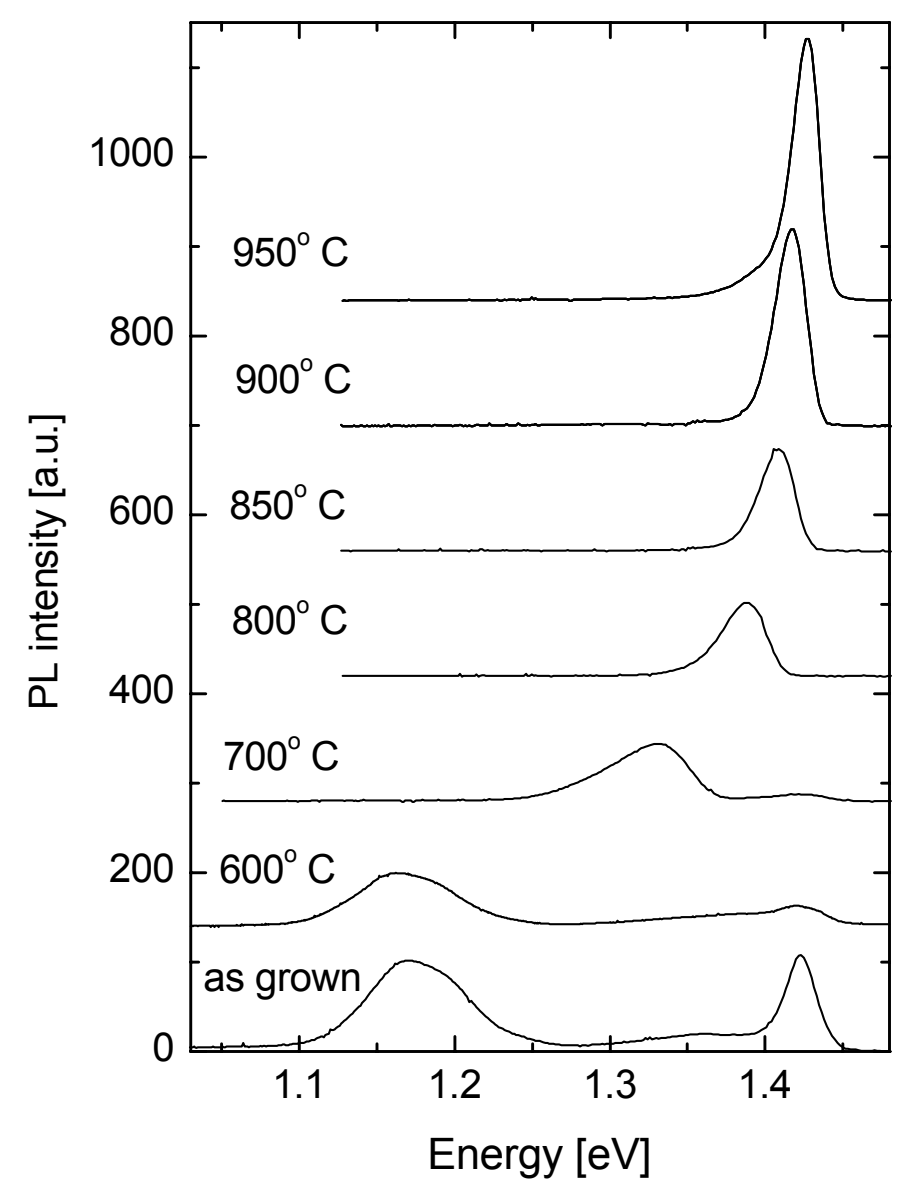

Figure 3

Fig. 3/5 APL A.Babinski et al 